\title{
Pescadores, hidroelétricas e novos ordenamentos territoriais dos rios amazônicos
}

\author{
Pescadores, hidroeléctricas y nuevas ordenaciones territoriales \\ de los ríos amazónicos
}

Fishermen, hydroelectric plants and new Amazonic rivers
territorial planning

\author{
Luís Augusto Pereira Lima \\ aplluis@yahoo.com.br \\ Universidade Federal de Rondônia, UNIR, Porto Velho, RO \\ Ricardo Gilson da Costa Silva \\ rgilson@unir.br \\ Universidade Federal de Rondônia, UNIR, Porto Velho, RO
}

Resumo: As hidroelétricas representam um dos maiores desafios às comunidades tradicionais ribeirinhas, principalmente quando essas barragens produzem um novo ordenamento territorial dos rios amazônicos. O texto analisa três situações que envolvem pescadores artesanais e a construção, planejamento e operação de hidroelétricas na Amazônia, localizadas nas cidades de Porto Velho (Rondônia), Tucuruí (Pará) e Caracaraí (Roraima). A metodologia qualitativa ateve-se a trabalhos de campo, consulta a referenciais teóricos e sistematizações referentes às problemáticas vivenciadas pelas comunidades de pescadores. Conclui-se que o ordenamento dos rios amazônicos busca impor uma invisibilidade programada aos pescadores e suas comunidades, desconstruindo territórios de vivências culturais para afirmar territórios de mercantilização do capital hidroelétrico. As hidroelétricas continuam a se instalar, mapeando as potencialidades energéticas em territórios tradicionais/culturais definidos nos zoneamentos da Amazônia. A segurança outrora garantida na lei acerca dos territórios das comunidades tradicionais passa agora por uma revisão das áreas protegidas, apontando uma agenda de conflitos socioterritoriais Amazônia brasileira. Palavras-chave: Amazônia, Desterritorialização, Comunidades tradicionais.

Resumen: Las represas hidroeléctricas representan uno de los mayores desafíos para las comunidades ribereñas tradicionales, especialmente cuando estas represas producen un nuevo ordenamiento territorial de los ríos amazónicos. El texto analiza tres situaciones que involucran a pescadores artesanales y la construcción, planificación y operación de represas hidroeléctricas en la Amazonía, ubicadas en las ciudades de Porto Velho (Rondônia), Tucuruí (Pará) y Caracaraí (Roraima). La metodología cualitativa se centró en el trabajo de campo, consulta con referencias teóricas y sistematizaciones referidas a los problemas experimentados por las comunidades pesqueras. Se concluye que el ordenamiento de los ríos amazónicos busca imponer una invisibilidad programada a los pescadores y sus comunidades, deconstruyendo territorios de experiencias culturales para afirmar territorios de mercantilización del capital hidroeléctrico. Las represas hidroeléctricas continúan a llegar y mapean las potencialidades energéticas 
en los territorios tradicionales / culturales definidos en la zonificación amazónica. La seguridad que una vez estuvo garantizada bajo la ley de territorios de comunidades tradicionales ahora pasa por una revisión de áreas protegidas, indicando una agenda de conflictos socio-territoriales en la Amazonía brasileña.

Palabras clave: Amazonía, Desterritorialización, Comunidades tradicionales.

\begin{abstract}
Hydroelectric plants represent one of the biggest challenges do traditional communities, especially when these dams produce new territorial planning of Amazonia Rivers. The text analyzes three situations involving fishermen and hydroelectric plants building, planning, and operation in Amazonia, located in Porto Velho (Rondônia), Tucuruí (Paraná) and a Caracaraí (Roraima) cities. The qualitative methodology conformed to field works, theoretical material examination and systematization referring to problems related to fishermen communities. We concluded that the hydroelectric plants planning has searched to impose programmed invisibility of the fishermen and their communities, distanced themselves from a territory of cultural experiences for the territory of the commodification of the Amazonian rivers. Hydroelectric plants keep coming and mapping energetic potentiality on Amazonia zonings. The security previously assured by the law of traditional communities' territories is now being reviewed about protected areas indicating an Amazonia socio territorial conflicts agenda.
\end{abstract}

Key words: Amazonia, Deterritorialization, Traditional communities.

\title{
INTRODUÇÃO
}

Na Amazônia brasileira, os pescadores artesanais e as comunidades ribeirinhas em suas particularidades constituem territorialidades, saberes e práticas na relação com o rio como parte de sua existência, extensão de suas vidas e dos territórios de pesca.

As relações se estabelecem sob um dado conhecimento prático informal, ampliado pela cultura e pela natureza em sua construção indissociável na vida ribeirinha. As condições da socialidade na Amazônia não se vinculam às usinas hidroelétricas (UHE), nem às recorrentes compensações ínfimas que essas empresas contrapõem às especificidades territoriais ribeirinhas. Na verdade, na atualidade, a ampliação de grandes projetos hidroelétricos confere instabilidades territoriais aos pescadores, sejam ribeirinhos, tradicionais, artesanais, associados em colônias e outras organizações, sejam de outras categorias, como aqueles atingidos por barragens. Esse panorama do pescador, essencialmente aquele em que a relação com o rio manifesta a indivisibilidade do trabalho e tradicionalidade, perpassa a construção de cada hidroelétrica na Amazônia.

Neste contexto, observa-se uma gama de grandes projetos hidroelétricos que se sobrepõem às territorialidades de muitas comunidades tradicionais. Isso significa impactos de natureza diversa num dos maiores vínculos de existência territorial na Amazônia, que são os recursos hídricos, ou seja, a relação dinâmica e íntima com os rios e sua importância para a resistência e autonomia dos pescadores em seus territórios tradicionais.

Referente a esses vínculos, o texto se propõe a construir uma reflexão das situações localizadas de pescadores dos municípios de Porto Velho (Rondônia) com as UHE Jirau e 
Santo Antônio, ambas em operação; de pescadores de Tucuruí (Pará) com a UHE Tucuruí, em operação; e dos pescadores de Caracaraí (Roraima) com a planejada UHE Bem Querer.

Como procedimento metodológico qualitativo procedeu-se à consulta de referenciais teóricos, documentos e relatórios públicos de planejamento energético, trabalhos de campo e observação direta dos processos que qualificamos como situações localizadas dos pescadores. Os trabalhos de campo foram realizados em períodos alternados: em 2016 priorizou-se Tucuruí (PA), em 2017 e 2018 as observações de campo foram realizadas em Porto Velho (RO), Boa Vista e Caracaraí (RR).

Tais situações, em suas disparidades e contrastes, podem ser um suplemento positivo aos debates referentes à região, sobretudo, por considerarmos que ainda estão em curso diversos projetos para viabilizar hidroelétricas na Amazônia. Ressalta-se que o Estado e as grandes empresas articulam narrativas desses sistemas de objetos para a Amazônia na perspectiva de sua integração territorial e modernização regional, configurando o que Becker (2004) qualificou de malha programada para a modernização do território.

Portanto, o artigo discute os processos relacionados ao ordenamento do território em curso, que a partir das hidroelétricas atingem aos pescadores ribeirinhos (LIMA; COSTA SILVA, 2018), resultando em restrições aos territórios tradicionais nos distintos locais estudados. O ordenamento do território é imposto às comunidades ribeirinhas e aos territórios tradicionais como ato concreto, para depois ser juridicamente ordenado na condição de território como norma, ou seja, o território regido e acionado pelos mecanismos de poder das empresas (SANTOS, 1996; COSTA SILVA; LIMA; CONCEIÇÃO, 2018).

Assim, estruturamos o texto em dois blocos de análise. No primeiro se discute a relação política entres pescadores (comunidades tradicionais), Estado e capital hidroelétrico na configuração territorial da Amazônia. Em seguida, analisa-se o processo político de ordenamento do território sob a ação do capital em desfavor dos pescadores, priorizando os depoimentos dos sujeitos que vivenciam a erosão programada de seus espaços tradicionais e de suas territorialidades amazônicas. Nas considerações finais indica-se os processos centrais que nos permitiram sistematizar os desafios e situações dos pescadores amazônicos em defesa de seus territórios tradicionais.

\section{PESCADORES, HIDROELÉTRICAS E TERRITÓRIO NA AMAZÔNIA}

A construção de grandes projetos hidroelétricos na região amazônica contribui diretamente para a ampliação dos conflitos socioterritoriais com os povos indígenas e comunidades tradicionais (ribeirinhos, pescadores, quilombolas, extrativistas, seringueiros, dentre outros), quase sempre engendrando situações de reconfiguração econômica e jurídica dos territórios em disputa, ou seja, indica-se em curso novos ordenamentos do território (COSTA, 2008) que se traduzem em controle de área, matéria e fluxo pelo agente hegemônico (neste caso, capital hidroelétrico).

Esses processos cristalizam as estratégias do Estado brasileiro e das grandes empresas extrativas em propor construções de usinas hidroelétricas que normalmente se 
sobrepõem aos territórios tradicionais dos povos amazônicos, especialmente aos espaços de pesca das comunidades ribeirinhas. A questão se amplia na medida em que a expansão do parque hidroelétrico põe em relevo a questão dos direitos humanos relacionados ao direito ao território. Significa que a malha programada (BECKER, 2004) ou o sistema territorial (RAFFESTIN, 1993) do Estado, associado ao capital nacional/internacional, captura e controla o espaço das comunidades tradicionais, ordenando-os como território do capital/Estado (HAESBAERT, 2006), os quais se reconfiguram a partir de um sistema de forças políticas que modelam o território com outros símbolos, normas, narrativas, cartografias e representações (COSTA, 2008; LIMA; COSTA SILVA, 2018).

Porto-Gonçalves (2008) qualificou as transformações espaciais da Amazônia em duas formas de configuração territorial que deslocam o eixo econômico e social da região. Para o autor, nas últimas décadas há uma paulatina substituição do padrão espacial centrado no eixo rio-várzea-floresta, que apresentava o extrativismo sem grandes tecnologias como modelo de uso do território, para a organização espacial estrada-terra firme-subsolo, que indica a exploração da natureza assentada em grandes projetos neoextrativistas. Pode-se aludir que há uma combinação desses padrões, dessas formas de organização do espaço amazônico evidenciada pela ação de agentes hegemônicos na estratégia de exploração dos recursos da natureza em toda a Amazônia, observando principalmente as sub-regiões em que não existe uma base técnica em infraestrutura, em sistemas de engenharia (SANTOS, 1996) que possam garantir um alicerce sólido ao deslocamento do capital em diferentes mosaicos socioespaciais amazônicos (terra, floresta, rio).

A malha programada de controle técnico e político dos fluxos para modernização territorial da Amazônia (BECKER, 2004), efetivada em planos e programas do governo federal desde 1960, indica não somente o controle dos territórios, mas a desterritorialização de comunidades tradicionais (pescadores) que há décadas vivem em espaços comunitários, de livre acesso à natureza, sem necessariamente ser modelada por instrumentos jurídicos, normativos, de restrição social. Por isso, são considerados territórios tradicionais que reúnem os grupos humanos, assegurando a reprodução sociocultural em bases naturais, de pertencimento e indissociabilidade desses grupos com a natureza. Suas regras e mediações são pautadas em códigos sociais de ancestralidades não parametrizados pela lógica formal da racionalidade do capital.

As dinâmicas territoriais produzidas pelas UHEs impactam especialmente os significados simbólicos dos territórios de pesca, no sentido de alterar a prática e a apropriação territorial dos pescadores. As territorialidades dos pescadores representam um dinamismo sociocultural complexo que não se molda às utilidades propostas pelos projetos e planos referidos às hidroelétricas. Trata-se de um sentido de territorialidade que se materializa em múltiplos processos da relação sujeito/ser humano para com a natureza/território, conforme se observa nas argumentações de Guedes (2011, p. 55), em comunidades de pescadores do estado do Pará:

A territorialização destas coletividades humanas se torna materializada quando se percebe a delimitação de seus territórios a partir da apropriação e uso onde os 
pescadores são capazes de delimitar mentalmente estes recortes espaciais e mesmo representá-los através de mapas mentais, formando uma malha política que emerge do poder de forças localizadas que mesmo não sendo reconhecidas e legitimadas pelo poder estatal são pertinentes como forma de assegurar seus domínios de vivência e reprodução, isto é, sua territorialidade.

Os pescadores têm como estratégias de trabalho, do produto de seu esforço individual e coletivo, a alternância com o extrativismo, agricultura, caça e pesca, constituindo verdadeiros processos laborais que transcendem a interpretação da legislação (LIMA, 2015). A exemplo, cita-se o Decreto no 8.967 de 23 de janeiro de 2017, que classifica o registro da atividade pesqueira como única e exclusiva fonte de renda para o pescador (a) impondo a escolha entre ser ou não ser pescador (a) para então estar-se candidato aos "benefícios" e amparo da lei.

Firth (1975), ao estudar os pescadores malaios, destaca a multidimensionalidade do trabalho destes pescadores, uma vez que a cultura principal do agricultor é geralmente também o seu alimento básico, mas como o pescador não vive somente de peixes, ele também cultiva arroz e outros gêneros alimentícios paralelamente à pesca. $\mathrm{O}$ autor relata que pescadores associam a pesca ao extrativismo de maneira a equilibrar a sua reprodução física e social, considerando que os membros da unidade do trabalho familiar podem incluir agricultores e pescadores em seus grupos. As normas e decretos nacionais incidem diretamente na alternância do trabalho e da apropriação do território, definindo o que é o mundo do trabalho dos pescadores, ignorando o mundo do trabalho das comunidades de pescadores na Amazônia. Igualmente, tendem a impactar a consulta das empresas construtoras das usinas, que na elaboração de seus relatórios socioeconômicos das comunidades atingida, não raro classificam como pequenos agricultores ou ribeirinhos os moradores das margens e adjacências dos rios, sem mencionar os pescadores de fato.

O capital hidroelétrico que impõem formas aos rios e aos territórios provê uma nova morfologia do território, muitas vezes privando os pescadores de acesso ao rio (SEVÁ FILHO, 2004). O ordenamento imposto pelas hidroelétricas qualifica o território como relação de poder, transcrito na espacialidade do capital. No sentido de afastar, apartar e impedir, prevalece o território como material e como norma. O afastar expressa o impedimento aos pescadores, ribeirinhos e outras categorias/grupos sociais. Nesse sentido, impõem-se novas dinâmicas territoriais dos pescadores com restrições aos rios ou às áreas de reprodução social, deslocadas e, algumas, convertidas em expressões urbanas ou lagos artificiais. Esses processos em transformação e de ressignificação territorial são direcionados à construção de novos espaços planejados e estranhos a socialidade ribeirinha e suas territorialidades, sem a identidade de suas relações. Nessa perspectiva, vê-se o território dos pescadores sobrepostos ou assumidos pelas usinas como outro ordenamento territorial, um território da racionalidade do capital, da natureza como mercadoria.

A lógica do medo e da dominação no processo de instalação das hidroelétricas refazem os cursos dos rios e desfazem as vidas dos pescadores e comunidades atingidas, $\mathrm{O}$ que normalmente os conduz as incertezas das compensações financeiras e às "esmolas" das hidroelétricas. A disputa atrelada a força do capital "empreendedor" das empresas 
busca, com ampla propaganda na mídia regional, justificar as políticas governamentais de desterritorialização das comunidades ribeirinhas e, particularmente, dos pescadores artesanais (LIMA; COSTA SILVA, 2018).

\section{REORDENAMENTO TERRITORIAL E INVISIBILIDADE PROGRAMADA DOS PESCADORES}

Pelo exposto, está em curso um ordenamento territorial dos rios amazônicos, que passa pela racionalidade espacial do capital hidroelétrico (SANTOS, 1996; COSTA SILVA; LIMA; CONCEIÇÃO, 2018; CAVALCANTE et al., 2011), entendido como um programa de afastamento dos povos e comunidades tradicionais do acesso aos recursos hídricos e de seus territórios culturais (LIMA; COSTA SILVA, 2018). Adiciona-se a essas dinâmicas territoriais outros ordenamentos na região que igualmente ditam a racionalidade espacial do capital, como a agenda territorial das mineradoras, dos sistemas portuários do agronegócio, da ampliação das rodovias, da pressão para revisão de unidades de conservação e do mercado global de terras (MELLO-THÉRY, 2011; COSTA SILVA, 2017). Essas agendas territoriais implicam na modificação jurídica de unidades de conservação e de territórios tradicionais/culturais, servindo como motores da expansão da fronteira agrícola na Amazônia, como atualmente ocorre no sul do estado do Amazonas e no oeste do Pará (CONCEIÇÃO RIBEIRO; COSTA SILVA, 2019).

De modo geral, enquanto há uma reorganização das áreas afetadas e convertidas em território das grandes empresas hidroelétricas, tem-se a desterritorialização das comunidades de pescadores, fragmentação social e estranhamentos aos lugares reservados a essas comunidades, não raras vezes se configurando em espaços indefinidos, inclusive em sua condição jurídico-territorial. Experiências localizadas das comunidades de pescadores priorizadas neste estudo se refere à situações sociais em contextos emblemáticos de disputas de territórios, compostas por relações de poder, controle do território, redução de área, restrição aos recursos naturais (rio, pescado e produtos extrativos da floresta).

Para isso, cartografamos as cidades, comunidades de pescadores e hidroelétricas. Evidencia-se que o planejamento e a instalação de usinas hidroelétricas impõem uma escala geográfica local/regional/nacional que alcança sub-regiões amazônicas indicadas na Figura 1 (três pontos) que vem experimentando restrições com o ordenamento territorial das UHEs. É possível verificar também marcações em vermelho que indicam novas hidroelétricas que poderão reordenar as vivências nos territórios tradicionais. Observa-se que as rodovias federais projetam uma conexão a ser explorada no espaço regional que atualmente se intensifica em termos de planejamento e ação dos agentes políticos e econômicos regional nas pressões políticas para a pavimentação da BR-319 (Manaus-Porto Velho). 
Figura 1 - Localização das hidroelétricas e área de estudo (2019).

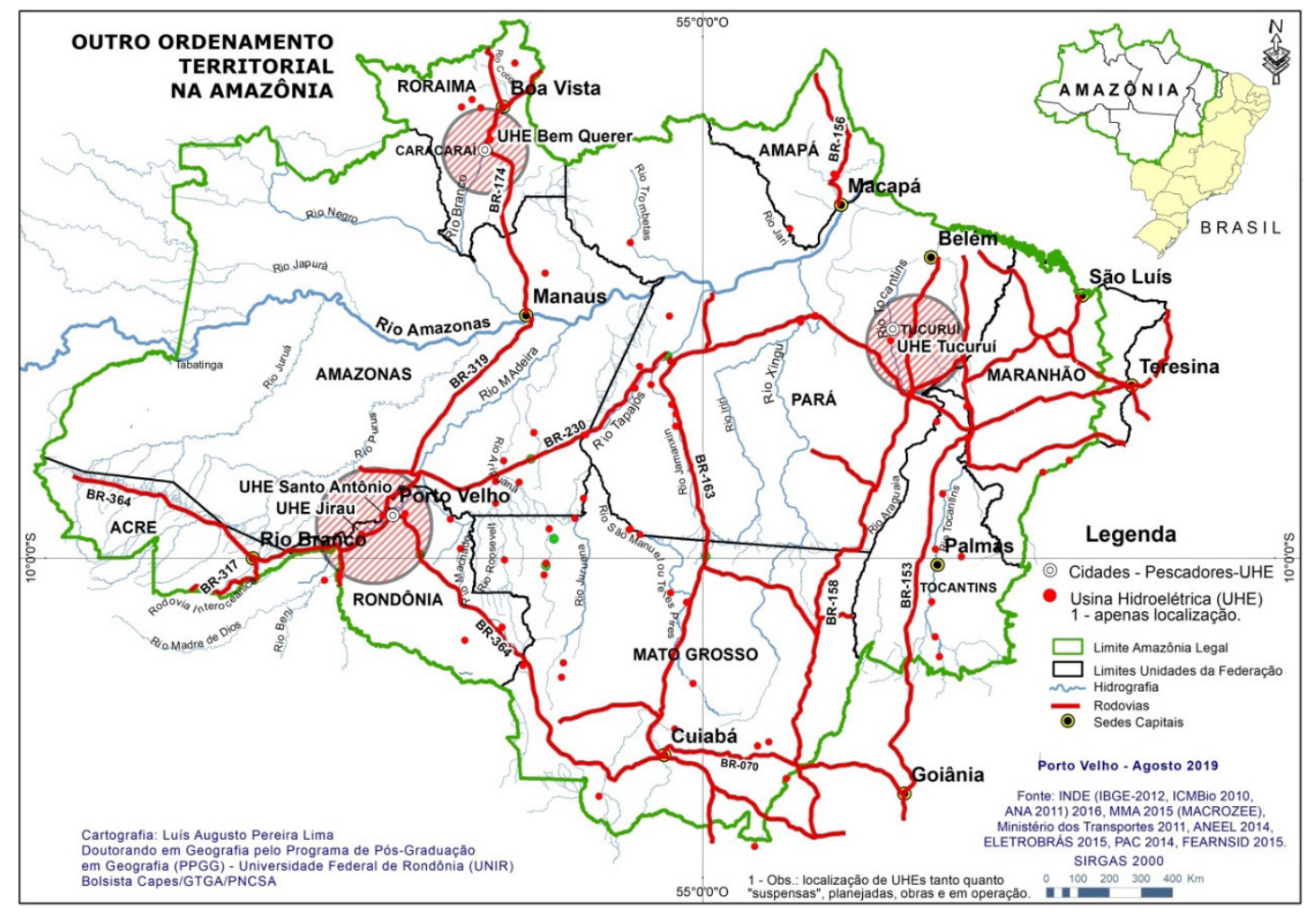

Fonte: os autores.

Associa-se relações de poder existenciais ou reprodutivas (RAFFESTIN, 1993), além de controle do território com restrições aos pescadores e acesso aos rios. Em Saquet (2007) esse processo se descortina na relação das forças econômicas, políticas e culturais que condicionam territórios e territorialidades, sobretudo, quando as ínfimas compensações ambientais dos grandes projetos tecem a configuração do espaço amazônico como um ordenamento territorial em curso. Em regiões objeto de construção de hidrelétricas, os pescadores passam por uma forte incorporação espacial, verdadeira psicoesfera do capital e tecnosfera do medo (SANTOS, 1996), sobretudo quando vêm seus territórios de pesca redefinidos e as vezes transplantados às geometrias urbanas (bairros, vilas, reassentamentos urbanos, condomínios precários), fragmentando seus modos de vida e suas territorialidades. Mesmo quando o remanejamento ocorre na área rural (assentamentos rurais), há uma ruptura ao deixarem de vivenciar a territorialidade ribeirinha para "experienciar" um cotidiano de assentado, de agricultor, muitas vezes localizados à distância dos rios, do universo de pertencimento, afastado da socialidade extrativista-comunitário.

Os pescadores das comunidades do rio Madeira, no município de Porto Velho (RO), viram as UHE de Jirau e Santo Antônio serem construídas em seus territórios tradicionais, espaço de trabalho e de vida comunitária (Figura 2). A certeza de que as obras seriam realizadas era inevitável, e o que ocorreria com os pescadores também, conforme consta no depoimento de um membro da colônia de pescadores da região: 
“Tu já tem andado por aí, visto as usinas que são vista por aí, o que é que acontece com os pescadores? E onde tem usina num tem ninguém, jogam ele lá pro meio da cidade e aqui na periferia ele vai sofrer porque tira totalmente a cultura dele, ele vai rodar, rodar e cair lá na boca da beira do rio". Membro da Colônia de Pescadores Z-1 de Porto Velho, Outubro de 2008. (PNCSA, 2009, p. 4) Grifo nosso.

Em 2018, dez anos após a publicação do informativo do Projeto Nova Cartografia Social da Amazônia (PNCSA), estivemos na Colônia dos Pescadores em Porto Velho, na qual se constou a mesma sensação narrada há uma década. Segundo o senhor Valter, pescador aposentado, naquele momento: "Não restava nenhuma coisa boa. Porque a gente não pode mais pescar e o que recebemos não deu em nada".

A previsão do pescador assinala que muitas comunidades estariam "destinadas a desaparecer". Haveria uma subordinação às hidrelétricas, de modo que eles não poderiam rever nem acessar seus territórios de pesca. Seus destinos estariam "no meio da cidade, na periferia", sem as relações sociais e sem a proximidade com a natureza. Além do deslocamento compulsório, os pescadores foram excluídos de qualquer reparação identitária e de trabalho, uma vez que não poderiam mais exercer a pesca como atividade principal. Contudo, no processo de construção das usinas do rio Madeira, conforme argumentam Rainey e Rainey (2016, p. 241): "muitos pescadores afirmam que os impactos previstos sobre esta atividade já se fazem sentir, e alegaram que a captura de peixe diminuiu bastante desde a construção da barragem", nos poucos locais que ainda podiam acessar.

Figura 2 - Comunidades ribeirinhas impactadas pelas hidrelétricas do Madeira (2017).

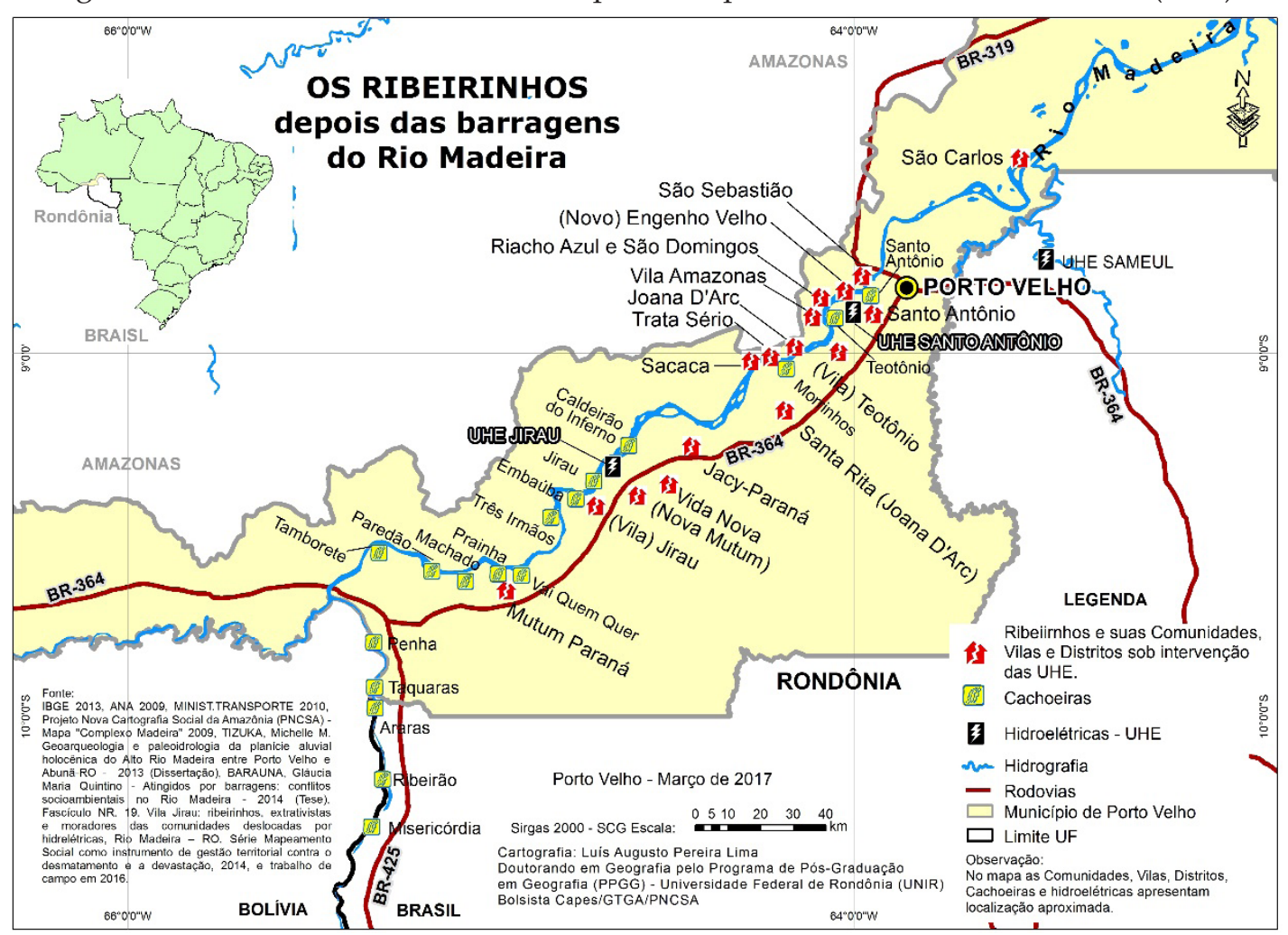

Fonte: COSTA SILVA; LIMA; CONCEIÇÃO, 2018. 
A desterritorialização dos pescadores e comunidades ribeirinhas da área de impacto das hidroelétricas do rio Madeira é a mais recente, e de algum modo se aproxima das experiências vividas pelos pescadores do rio Tocantins, em Tucuruí (PA), referenciada na Figura 1 logo ao sul de Belém, onde situam-se os pescadores ribeirinhos e a UHE Tucuruí no rio Tocantins. Esta, por sua vez, desde a década de 1970, causa danos aos pescadores e comunidades que utilizavam a pesca no rio Tocantins para a sua reprodução sociocultural. A questão socioambiental, segundo Esmael Rodrigues Siqueira1, seria que, "depois disso, da barragem do rio, veio a desgraça", os problemas sociais: "As comunidades organizadas pelo movimento, da beira do rio Tocantins que tinha a roça e a pesca para manter suas famílias, quando passava a equipe da Eletronorte, da Conspara [construtora], empresa da pesquisa, diziam pra nós: esses aí, são a turma do contra, contra a boa educação, contra a saúde. Tudo isso aí, vocês vão ter com a construção da usina".

Nas palavras do senhor Esmael, "fecharam o rio, a água baixou de vez e nada teve, nada de escola, nada de saúde. A sorte foi que cada comunidade tinha um igarapé central e salvou a todos". As comunidades foram removidas e muitos moradores foram deslocados para a cidade de Tucuruí, ocupando a periferia. Aqueles que permaneceram nos seus territórios perderam o rio, ficando apenas uma água "sem vida":

A nossa atividade que é pesca, não dá mais pra bóia, ninguém pega mais nem a bóia ${ }^{2}$, tá ai o peixe que vocês vão almoçar agora tá vindo de outro lugar, tá vindo de Pacajá, de Altamira, tá vindo filhote de lá, é o peixe de lá, porque aqui mesmo a Eletronorte, a barragem acabou tudo, o que tinha acabou. Senhor Ronaldo Adriano Moraes, Vila Caputeua, Junho/2013. (PNCSA, 2014b, p. 9) Grifo nosso.

A narrativa elabora as descrições de uma realidade ainda presente em muitos locais, ressaltando que a impossibilidade de se pescar e se pegar o peixe para a própria alimentação pode "acabar com tudo". As especificidades dos pescadores se fragmentam sob essa perspectiva imutável das usinas hidroelétricas. Como assinalou Haesbaert (2014, p. 57), observa-se um território "com a inspiração do terror e do medo", um sentido completo de deterioração, pois agora os pescadores seguem o "consumo urbano-industrial", distanciando-se da natureza e do ato de pescar.

Próximo a cidade de Boa Vista (RR), no curso do rio Branco, em Caracaraí (RR), localiza-se a UHE Bem Querer, prevista desde 2010 e sucessivamente adiada, agora prevista para atuar em 2020 (FEARNSIDE, 2015) ou mesmo 2021. Ela também traz consigo um conjunto de conflitualidades vinculadas a indústria da pesca e pesca esportiva, assim como com a criação de unidades de conservação, assumindo um conjunto de fatores que viabilizam a expropriação dos pescadores, agricultores e indígenas.

Em 2017, na feira do Tambaqui, em Boa Vista, entrevistamos o senhor Amadeu, pescador da região de Caracaraí. Ele nos relatou que "a usina ainda não tinha 'saído', mas já estava dando tanto problema pra eles [pescadores e moradores], que a solução foi se juntar com

1 Liderança da Associação das Populações Organizadas vítimas das obras do Rio Tocantins e Adjacências (APOVO, entrevista realizada em 2016 em Tucuruí (PA), durante trabalho de campo).

2 "Bóia", na linguagem ribeirinha, além de outros grupos sociais, significa alimentação, almoço, refeição. 
todos". Neste processo já se insere as ações ampliadas da indústria da pesca que se instalou fortemente em Roraima e constitui ameaça real às territorialidades dos pescadores:

A indústria da pesca que se instalou tem sido bastante desfavorável para os pescadores de pequeno e médio porte [...]. Para estes, o peixe é utilizado na alimentação cotidiana, sendo comercializado apenas o excedente da produção. Senhora Marilene, membro da Diretoria do Sindicato dos Pescadores de Caracaraí (PNCSA, 2014a, p. 3-4).

As relações que se estabelecem nesse contexto tendem a inviabilizar a base alimentar dos pescadores, pois com a indústria da pesca e a restrição aos locais de pesca artesanal tradicional a produção do pescado tende a se vincular mais ao mercado e menos à subsistência das famílias, modificando o fluxo econômico do pescador (Fig. 3).

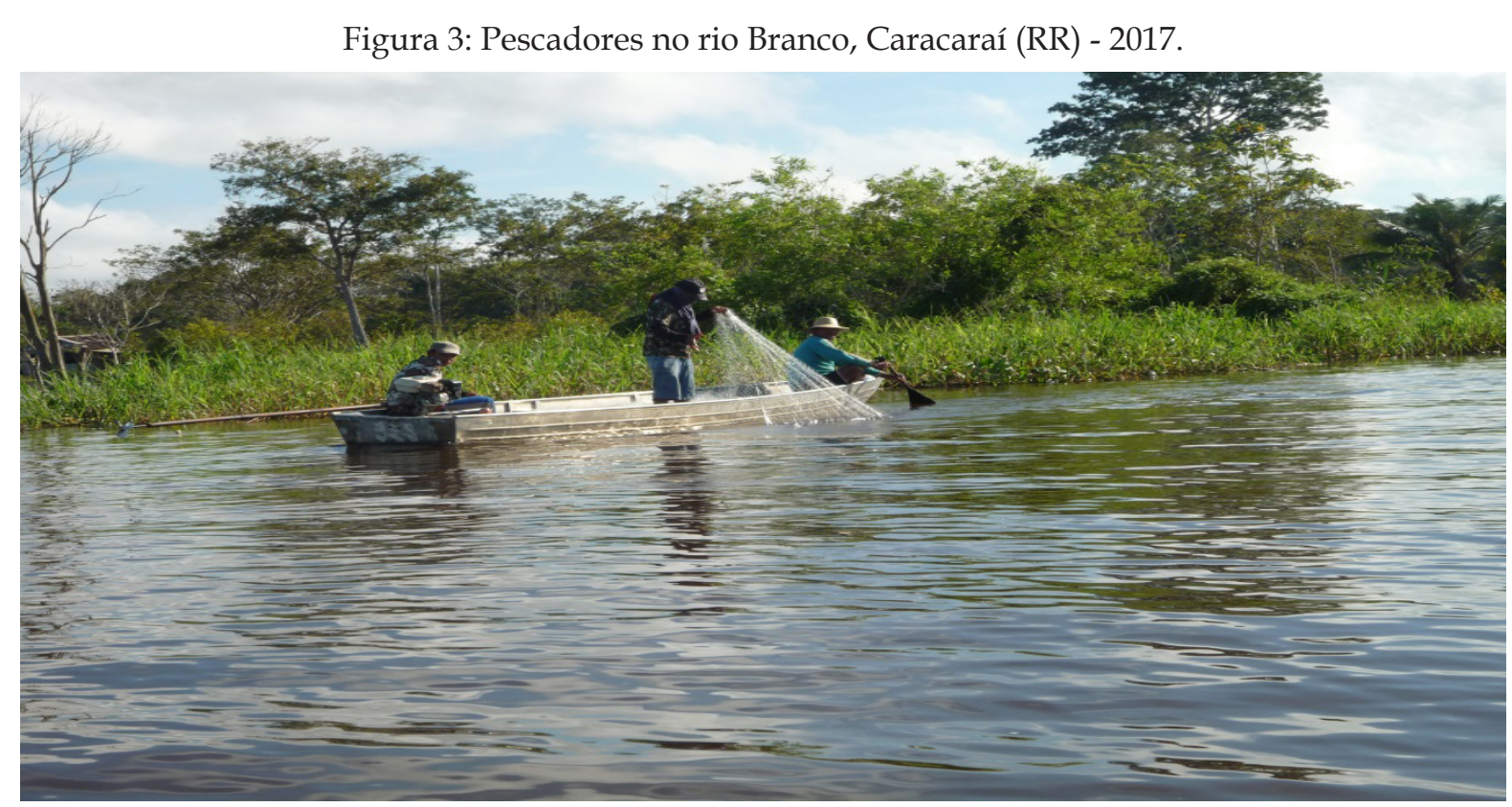

Fonte: Aglaia Costa.

O senhor Amadeu, pescador na área onde está prevista a construção da UHE Bem Querer, ressalta ainda que "as áreas de pesca praticamente desapareceram, seja pelas unidades de conservação, a intensa fiscalização ou com a usina, ficarão ainda mais reduzidas e no fim, não teremos onde pescar". A fala do pescador contempla o cenário de outros ordenamentos territoriais na Amazônia. Em relação às Unidades de Conservação constituídas, que não contemplaram os territórios de pesca em suas atribuições, agora empregam os órgãos fiscalizadores para impor impedimentos e restrições no acesso ao rio Branco e entorno, situação que antes não se colocava às comunidades tradicionais.

A seu modo, os pescadores mantêm formas resistência e mobilização, numa luta desigual frente à constituição de um deslocamento forçado do território, muitas vezes revertidos em reassentamentos como o resultado de lutas. Sobre isto, o senhor Euzébio, do Sindicado dos Pescadores de Caracaraí (PNCSA, 2014a, p. 5) relata que "as restrições ocasionadas também pela pesca esportiva incomoda [...] e o sentimento que prevalece é 
o de que foram expropriados de recursos que antes estavam ao seu alcance". Os afetados pela UHE Bem Querer se juntaram a campanha Salve o Rio Branco, por ação do sindicato dos pescadores, do Movimento Poraqué, de comerciantes, agricultores, pecuaristas, igrejas e sociedade civil em oposição ao projeto de hidrelétricas (Fig. 4).

Figura 4: Manifestação de pescadores e outros agentes sociais em oposição à UHE Bem Querer, Caracaraí/RR.

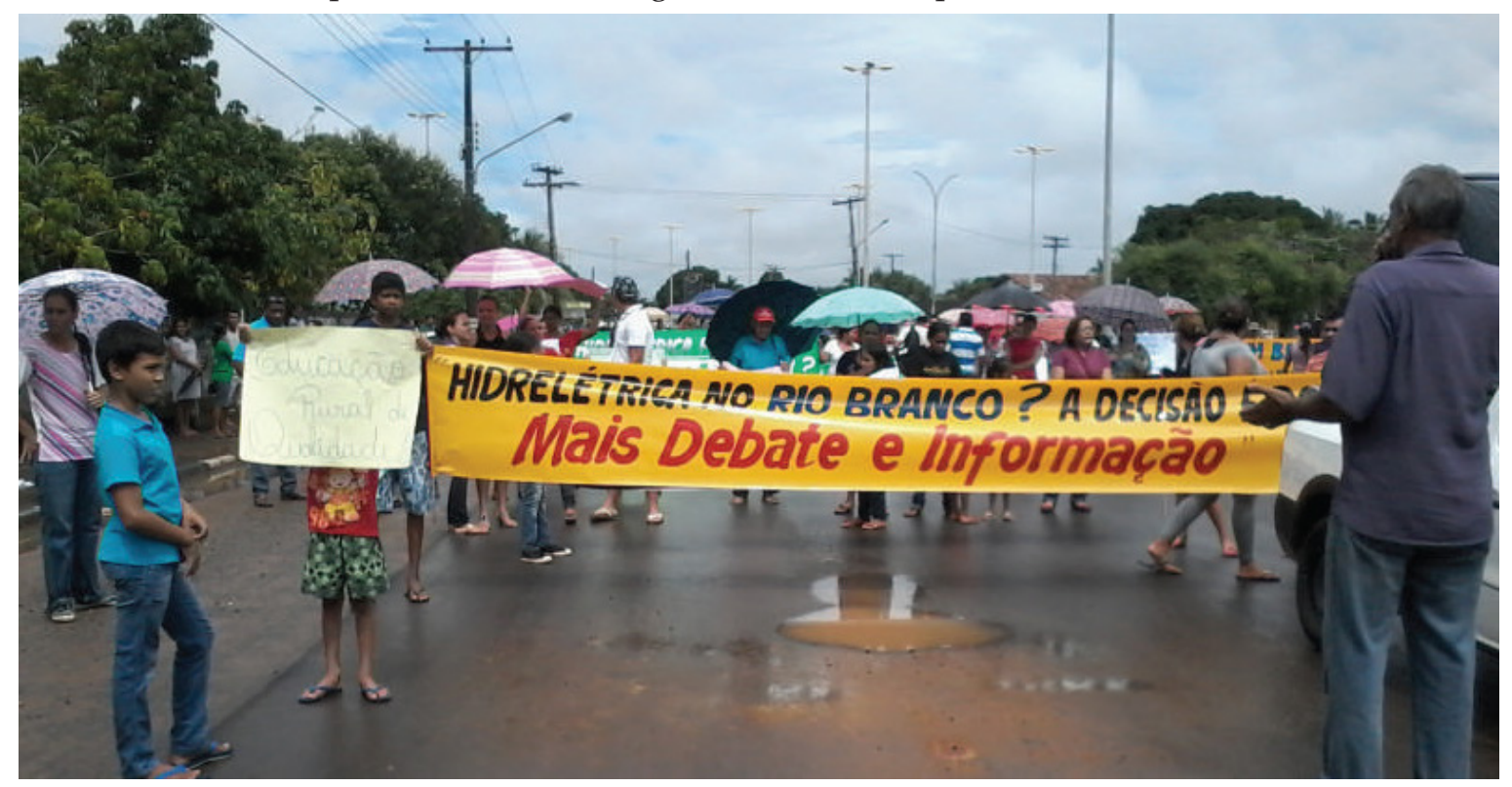

Fonte: PNCSA, 2014a.

Para o Estado e capital a escala geográfica de ação é nacional, na produção e comercialização da energia, enquanto os impactos sociais e territoriais surgem em escala local, sobretudo quando há expropriação, deslocamentos forçados e desterritorialização de comunidade tradicionais. Os pescadores do rio Madeira, em Porto Velho, estão no dilema da vida urbana, enquanto as hidroelétricas de Jirau e Santo Antônio estendem seus linhões ao Operador do Sistema Nacional (OSN), que já se conecta a UHE Tucuruí, onde os pescadores ainda lutam por direitos e pelo território de pesca. A UHE Tucuruí, por sua vez, conectou-se à Manaus (AM) como parte da integração ao sistema elétrico nacional, e em pouco tempo ter-se-á o linhão da UHE Bem Querer estendida até Manaus e ao OSN.

\section{CONSIDERAÇÕES FINAIS}

A cartografia realizada, além de oferecer uma ampla localização do que fora exposto inicialmente, também proporciona uma visão espacializada dos grandes projetos hidroelétricos, cujas ações alcançam os extremos amazônicos. As rodovias federais tecem as dinâmicas territoriais entre esses locais e sub-regiões e, ainda que incompletamente, já sinalizam ações, projetos e planos do governo brasileiro em se apropriar concretamente dos recursos da floresta e dos rios. 
A apropriação privada dos rios metamorfoseados em energia elétrica pelas usinas hidroelétricas implica em um outro ordenamento territorial dos rios amazônicos. A narrativa dos projetos hidroelétricos na Amazônia assenta-se na afirmação de que essas grandes infraestruturas são necessárias à modernização da região, indispensáveis ao crescimento econômico regional e nacional. Nesses termos, evidencia-se as escalas geográficas das estratégias políticas, econômicas e principalmente territoriais na Amazônia, considerando que a instituição desses projetos requer o controle do território e de seus recursos pelo capital. Portanto, a centralidade econômica é também territorial, ancorado tanto nas normas jurídicas que definem o que pode ou não ocorrer/usar no espaço territorializado, quanto na exclusão e desterritorialização de comunidades tradicionais.

Os pescadores, neste contexto de sobreposição e expropriação, têm seus territórios pautados em disputas com o planejamento estatal, cujo aparato político e econômico alicerça o caminho das hidroelétricas para ampliar sua territorialização na Amazônia, constituindo um modelo excludente de territórios tradicionais. Assim, o ordenamento do território das hidroelétricas busca impor uma invisibilidade programada dos pescadores e suas comunidades, distanciando um território de vivências culturais para um território de mercantilização dos rios amazônicos. Esses grupos sociais amazônicos aparecem na narrativa do capital e do Estado como obstáculos a serem retirados do caminho da modernização. Os estudos específicos constantes dos EIA/RIMA tendem a justificar a implantação dessas engenharias avançadas, e quase sempre não ampliam o conhecimento referente às territorialidades ribeirinhas, o que termina por induzir um entendimento empobrecido desses grupos sociais.

As empresas e o governo combinam os padrões de ordenamento, definem a apropriação dos conceitos para análise dos sujeitos, criando outro ordenamento como instrumento de prática e ação normativa, sem permitir que as realidades narradas a partir dos sujeitos afetados sejam alçadas ao debate ou quando são elencadas passam a ser subsumidas nos instrumentos de compensação socioambiental. Resulta a fragmentação dos territórios culturais das comunidades ribeirinhas, nas quais os pescadores afirmam sua identidade, territorialidades e lutas em resistir ao processo de expropriação.

As hidroelétricas continuam "chegando" e mapeando as potencialidades energéticas em territórios tradicionais/culturais definidos nos zoneamentos da Amazônia. A segurança que outrora estava garantida com a instituição, na forma da lei, de territórios das comunidades tradicionais, passa agora por uma revisão das áreas protegidas, indicando outros ordenamentos territoriais na região amazônica.

NOTA: A pesquisa contou com apoio das instituições: FAPERO, DHJUS/EMERON; PPGG/UNIR/CAPES.

\section{REFERÊNCIAS}

BECKER, Bertha. Amazônia: geopolítica na virada do III milênio. Rio de Janeiro: Garamond, 2004. 
CAVALCANTE, M.M.A; NUNES, D.D; COSTA SILVA, R.G.; LOBATO, L.C.H. Políticas territoriais e mobilidade populacional na Amazônia: contribuições sobre a área de influência das hidrelétricas no rio Madeira (Rondônia/Brasil). Confins, v. 11, p. 1-18, 2011. Disponível em: http://confins.revues.org/6924 Acesso em: 20 jul. 2017.

CONCEICAO, Francilene Sales da; RIBEIRO, Alyson Fernando A; COSTA SILVA, Ricardo Gilson. (Des)encontros entre a estrada e o rio: o caso da Gleba da Bota no oeste da Amazônia paraense. Revista Geonordeste, v.30, n.1, p. 6-25, 2019. doi.org/10.33360/RGN.2318-2695.2019.i1p6-25.

COSTA, Wanderley. Ordenamento territorial e Amazônia: vinte anos de experiências de zoneamento ecológico-econômico. In: BATISTELLA, Mateus; MORAN, Emilio Frederico; ALVES, Diógenes S. (Orgs.). Amazônia: Natureza e sociedade em transformação. São Paulo: Ed. USP, 2008.

COSTA SILVA, Ricardo Gilson. Da apropriação da terra ao domínio do território: as estratégias do agronegócio na Amazônia brasileira. International Journal of Development Research, v. 7, n. 12, p. 1769917707, 2017. Disponível em: http://www.gtga.unir.br/?page_id=679. Acesso em: 20 jul. 2017.

; LIMA, Luís Augusto Pereira; CONCEIÇÃO, Francilene Sales da. Territórios em disputas na Amazônia brasileira: ribeirinhos e camponeses frente as hidrelétricas e ao agronegócio. Confins (Paris), v. 36, n. 36, p. 1-12, 2018. Disponível em: https://journals.openedition.org/confins/13980. Acesso em: 20 jul. 2017.

FEARNSIDE, Philip. Hidrelétricas na Amazônia: impactos ambientais e sociais na tomada de decisões sobre grandes obras. Manaus: INPA, 2015. Cap.1, p. 9-37.

FIRTH, Raymond W. The Fishing Industry in Malaya and Indonesia. In: Malay Fishermen: Their Peasant Economy. Cambridge, 1975. Cap. 1. p.1-27.

GUEDES, Eneias Barbosa. Território e territorialidade de pescadores no Marajó: o exemplo das localidades Céu e Cajuúna, Soure, PA. In: SILVA; SILVA (Orgs.) Pesca e territorialidades: contribuições para a análise espacial da atividade pesqueira. Belém, GAPTA/UFPA, 2011.

HAESBAERT, Rogério. Ordenamento Territorial. Boletim Goiano de Geografia, v.1, n.26, p. 117-124, 2006.

Viver no limite: território e multi/transterritorialidade em tempos de in-segurança e contenção. Rio de Janeiro: Bertrand Brasil, 2014.

LIMA, Luis Augusto Pereira. A roça como categoria de análise e de afirmação identitária: Estudo da relação dinâmica de resistência e garantia do território em situações sociais referidas a quilombolas e indígenas. São Luís, 2015. Dissertação (Mestrado em Cartografia Social e Política da Amazônia) - Universidade Estadual do Maranhão, UEMA.

; COSTA SILVA, Ricardo Gilson. Cartografia das hidroestratégias na Amazônia brasileira. Acta Geográfica, Boa Vista, v.12, n.28, p. 129-142, jan./abr. 2018. Disponível em: https://revista.ufrr.br/ actageo/article/view/4510. Acesso em: 20 jul. 2017.

MELLO-THÉRY, Neli. Território e Gestão Ambiental na Amazônia: terras públicas e os dilemas do Estado. São Paulo: Annablume, 2011.

PNCSA - Projeto Nova Cartografia Social da Amazônia. Complexo Madeira - Conflitos Sociais na PanAmazônia. Organizado por Alfredo Wagner B. de Almeida et al. Manaus: UEA Edições / PPGAS-UFAM, 2009. (Boletim Informativo, 2).

. A luta dos trabalhadores rurais e pescadores de Caracaraí (RR) em defesa de seus direitos. Mapeamento Social como Instrumento de Gestão Territorial contra o Desmatamento e a Devastação: processo de capacitação de povos e comunidades tradicionais. Manaus: UEA Edições, 2014. (Caderno Nova Cartografia, 9).

Atingidos pela hidrelétrica de Tucuruí. Mapeamento Social como Instrumento de Gestão Territorial contra o Desmatamento e a Devastação: processo de capacitação de povos e comunidades tradicionais. Manaus: UEA Edições, 2014. (Caderno Nova Cartografia, 10).

PORTO-GONÇALVES, Carlos Walter. Amazônia, Amazônias. 2.ed. São Paulo: Contexto, 2008.

RAFFESTIN, Claude. Por uma geografia do poder. São Paulo: Ática, 1993. 
RAINEY, Steve J.; RAINEY, Maura C. Araújo. Perspectivas ribeirinhas sobre os impactos da construção de usinas hidrelétricas no Rio Madeira. In: COSTA SILVA, Ricardo G. (Org.) Porto Velho, cultura, natureza e território. Porto Velho: Temática/ Ed. UFRO, 2016. p. 234-260.

SANTOS, Milton. A natureza do espaço: Técnica e tempo, razão e emoção. São Paulo: HUCITEC, 1996.

SAQUET, Marcos A. Abordagens e concepções de território. São Paulo: Expressão Popular, 2007.

SEVÁ FILHO, Arsênio O. Conhecimento crítico das mega hidrelétricas: para avaliar de outro modo alterações naturais, transformações sociais e a destruição dos monumentos fluviais. In: ENCONTRO NACIONAL DA ANPPAS, 2. 2004. Indaiatuba. Anais Eletrônicos... Disponível em: www.anppas.org.br. Acesso em: 20 jul. 2017.

Data de submissão: 27/jul./2017

Data de aceite: $24 /$ jul./2019 